\title{
Pulmonary Mycobacterium tuberculosis in acquired immune deficiency syndrome
}

\author{
N DOBLE, P HYKIN, R SHAW, E E KEAL
}

\begin{abstract}
A case of pulmonary infection with Mycobacterium tuberculosis in a patient with the acquired immune deficiency syndrome (AIDS) was studied. Diagnosis of AIDS was confirmed by the finding of pulmonary $M$ tuberculosis with oral and oesophageal candidiasis accompanied by characteristic immunological changes with evidence of infection with human $T$ cell lymphotropic virus III.

Treatment of this patient was complicated by an unusual drug interaction between rifampicin and ketoconazole, leading to subtherapeutic serum concentrations and poor clinical response to treatment. Intravenous treatment was more effective than oral treatment.

This drug interaction should be studied in greater detail as ketoconazole and rifampicin may be used together to treat patients with candidiasis and infection with $M$ tuberculosis.
\end{abstract}

\section{Introduction}

The acquired immune deficiency syndrome (AIDS) is characterised by opportunistic infections. Pulmonary infection with atypical mycobacteria has been reported in the United Kingdom. We report a case of pulmonary infection with Mycobacterium tuberculosis in a patient with AIDS in the United Kingdom.

\section{Case report}

A 23 year old sexually active homosexual West Indian presented with a four week history of cough, fever, sweating during the night, and loss in weight. On examination he was feverish with generalised lymphadenopathy, oral candidiasis with buccal mucosal plaques, and crepitations in both lung

Department of Chest Medicine, St Mary's Hospital, London W2 1NY

N DOBLE, BSC, MRCP, registrar

P HYKIN, BSC, MB, house physician

R SHAW, MRCP, senior registrar

E E KEAL, MD, FRCP, consultant physician

Correspondence to: Dr Keal. fields. His haemoglobin concentration was $112 \mathrm{~g} / \mathrm{l}$; white cell count $7 \cdot 1 \times 10^{9} / 1$ with $6 \cdot 5 \times 10^{9} / 1$ neutrophils and $0.4 \times 10^{9} / 1$ lymphocytes; and arterial oxygen pressure $10.64 \mathrm{kPa}(80 \mathrm{~mm} \mathrm{Hg})$ and arterial carbon dioxide pressure $3.8 \mathrm{kPa}(29 \mathrm{~mm} \mathrm{Hg})$. A radiograph of his chest (figure) showed extensive consolidation of the right upper and middle lobes and the apical segment of the left lower lobe, and a Ziehl-Neelsen stain of sputum showed many acid fast bacilli, which were confirmed on culture to be $M$ tuberculosis, fully sensitive to antituberculous antibiotics. Bronchoscopy was normal and bronchial washings, stained by the Ziehl-Neelsen method, were positive for acid fast bacilli. Transbronchial biopsies were negative for cytomegalovirus

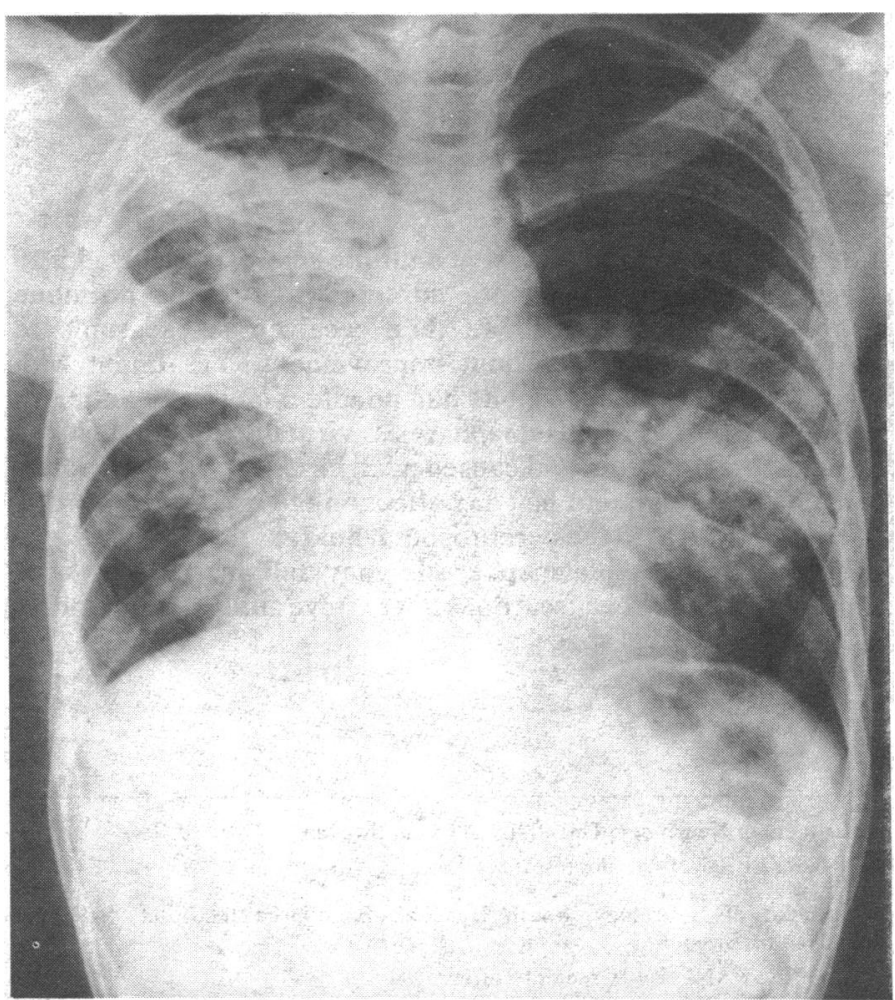

Radiograph of chest showing extensive consolidation of right upper and middle lobes and apical segment of left lower lobe. 
and Pneumocystis carinii. Barium swallow showed extensive deep ulceration with formation of plaques, consistent with oesophageal candidiasis, and a Mantoux test ( 1 in $10000 \mathrm{U}$ ) was positive, but there was no reaction to intradermal candida.

Two weeks after presentation the total circulating $T$ cell count was $1 \cdot 2 \times 10^{9} / 1$, T $40.56 \times 10^{9} / 1$, and T8 $0.44 \times 10^{9} / 1$; and antibodies to the human T cell lymphotropic virus type III (HTLV-III) were detected by membrane immunofluorescence. These results confirmed the diagnosis of AIDS based on the finding of pulmonary $M$ tuberculosis with oral and oesophageal candidiasis accompanied by characteristic immunological changes and evidence of infection with HTLV-III.

Five weeks' treatment with ethambutol, pyrazinamide, rifampicin, isoniazid, nystatin, and ketoconazole resulted in no clinical improvement and a persistent fever. Two hours after administration plasma rifampicin concentrations, measured by high pressure liquid chromatography after extraction of plasma with methylene chloride, were $<0.5 \mathrm{mg} / \mathrm{l}$ when rifampicin and ketoconazole were given concurrently, $2 \mathrm{mg} / \mathrm{l}$ when given 12 hours apart, and $3 \mathrm{mg} / \mathrm{l}$ after intravenous rifampicin only. Serum ketoconazole concentrations measured by a broth dilution bioassay were $0 \mu \mathrm{g} / \mathrm{l}$ when the oral doses were separated by 12 hours and $0.3 \mathrm{mg} / \mathrm{l}$ when oral ketoconazole was given 12 hours after intravenous rifampicin. After the introduction of intravenous rifampicin the patient's condition improved and his fever resolved. After two weeks oral amphotericin was substituted for ketoconazole, and he remained without fever when oral rifampicin was restarted.

\section{Discussion}

$M$ tuberculosis causing pulmonary disease in association with AIDS has been reported mainly in the Haitian population in America suffering from AIDS. ${ }^{1-3}$ As a result of the prevalence of $M$ tuberculosis in the British population we may expect to see further cases of pulmonary $M$ tuberculosis in people suffering from AIDS in Britain. There may be variation in radiographic features, and in our case the radiograph of the chest showed more severe interstitial w changes than those found in other series. ${ }^{4}$

A drug interaction was also observed in our patient between rifampicin and ketoconazole, leading to subtherapeutic serum $C$ concentrations and poor clinical response to treatment. In a $\widehat{\supset}$ previous report of this interaction a reduction in absorption of $\overline{\bar{J}}$ rifampicin was postulated. ${ }^{5}$ Our limited number of measurements suggest that the relation may be more complex but that intravenous treatment is effective when judged on clinical criteria. Ketoconazole is the mainstay of treatment for candidiasis in patients with AIDS, : which responds poorly to topical agents. Ketoconazole and rif- $\overline{\bar{v}}$ ampicin are likely to be used together in this context, and it is important that this drug interaction is studied in greater detail.

We thank Dr P A Toseland and Professor D W R Mackenzie for measurement of drug concentrations; Dr A J Pinching for reviewing the article; and Miss R A Mace for preparing the manuscript.

\section{References}

1 Viera J, Frank E, Spira TJ, Landesman SH. Acquired immune deficiency in Haitians. $N$ Engl $\mathcal{f}$ Med 1983;308:125-9.

2 Pitchenik AE, Fischl M, Dickinson GM, et al. Opportunistic infections and Kaposi's sarcoma among Haitians: evidence of a new acquired immunodeficiency state. Ann Intern Med 1983;98: 277-84

Pape $\mathrm{W}$, Liataud $\mathrm{B}$, Thomas $\mathrm{F}$, et al. Characteristics of the acquired immunodeficiency syndrome Haiti. N Engl F Med 1983;309:945-50.

4 Pitchenik AE, Rubinson HA. The radiographic appearance of tuberculosis in patients with the acquired immune deficiency syndrome (AIDS) and pre-AIDS. Am Rev Respir Dis 1985:131:393

5 Englehard D, Stutman HR, Marks MI. Interaction of ketoconazole with rifampicin and isoniazid. N Engl f Med 1984;311:1681-3.

Accepted 17 fuly 1985)

\title{
Persistence of antibrain antibodies in cerebrospinal fluid during plasmapheresis for multiple sclerosis
}

\author{
B RYBERG, R PIRSKANEN
}

\begin{abstract}
A man with chronic progressive multiple sclerosis received a 10 day course of treatment with adrenocorticotrophic hormone without beneficial effect. He then received six sessions of plasmapheresis, again without improvement. Treatment with adrenocorticotrophic hormone had no effect on serum antibrain antibody titres, but plasmapheresis virtually eliminated the antibodies from serum and caused a fall in serum IgG concentrations; neither treatment had any effect on the IgG concentration and antibody titre in the cerebrospinal fluid.

Treatment with plasmapheresis may fail in patients with multiple sclerosis because it does not remove antibrain antibodies from the intrathecal space.
\end{abstract}

Department of Neurology, University of Lund, Sweden

BJÖRN RYBERG, MD, senior research fellow

Department of Neurology, South Hospital, Karolinska Institutet, S-100 64 Stockholm, Sweden

RITVA PIRSKANEN, MD, senior lecturer

Correspondence to: Dr Ryberg.

\section{Introduction}

Plasma exchange might well be expected to work in multiple sclerosis by removing humoral factors with gliotoxic, myelinotoxic, $\frac{\dot{5}}{3}$ and neuroelectric blocking properties; circulating immune complexes; and complement fixing antibrain antibodies of various specificities. ' Such treatment can reduce serum neuroelectric blocking activity ${ }^{2}$ and cerebrospinal fluid IgG concentrations in patients 옥 with multiple sclerosis, ${ }^{3}$ but so far therapeutic success has been $\stackrel{N}{\circ}$ limited. ${ }^{4}$

\section{Case report}

A 38 year old man was in the chronically progressive phase of multiple sclerosis, which had first developed in 1975 as a relapsing-remitting $\stackrel{C}{\bullet}$ disorder. Diagnosis was substantiated by clinical, neurophysiological, and $\overparen{D}$ cerebrospinal fluid findings. A 10 day course of treatment with adreno- ?+ corticotrophic hormone in March 1982 had no effect on his signs and 7 symptoms, which included reduced visual acuity, moderate spastic para- $O$ paresis, sensory disturbances of hands and legs, urgency of micturition, exaggerated tendon reflexes, and extensor plantar responses.

Because of increasing disability he was treated with six sessions of plasmapheresis in May and June 1982. On each occasion four litres of plasma were removed and replaced with electrolytes and albumin solution. There $\delta$ was no improvement in clinical state or brain stem auditory evoked response, and his condition continued to worsen. 